$5 \mid 1983$

Varia

\title{
Une quittance inédite avec signature de Pascal
}

Jean Mesnard

\section{OpenEdition}

\section{Journals}

Édition électronique

URL : http://journals.openedition.org/ccibp/415

DOI : $10.4000 /$ ccibp 415

ISSN : 2493-7460

\section{Éditeur}

Centre international Blaise Pascal

\section{Édition imprimée}

Date de publication : 5 juillet 1983

Pagination : 3-4

ISSN : 0249-6674

\section{Référence électronique}

Jean Mesnard, «Une quittance inédite avec signature de Pascal », Courrier du Centre international Blaise Pascal [En ligne], 5 | 1983, mis en ligne le 25 novembre 2015, consulté le 21 avril 2019. URL http://journals.openedition.org/ccibp/415; DOI : 10.4000/ccibp.415

Ce document a été généré automatiquement le 21 avril 2019

Centre international Blaise Pascal 


\title{
Une quittance inédite avec signature de Pascal
}

\author{
Jean Mesnard
}

1 L'attention des pascalisants, et d'abord celle du Centre International Blaise Pascal, a été récemment attirée par la mise en vente d'une pièce inédite intéressant l'auteur des Pensées : événement rarissime. Au sein d'une superbe collection d'autographes, dispersée au Nouveau Drouot les 14 et 15 décembre 1983 - le 15 pour la pièce qui nous retient figurait une quittance d'arrérages de rentes sur l'Hôtel de Ville, datée du 12 février 1652, quittance rédigée sur une feuille de vélin de forme oblongue, comme il est de règle pour ce genre de document: au bas, une magnifique signature de Pascal, avec paraphe. M. le Maire de la Ville de Clermont-Ferrand avait bien voulu soutenir généreusement les efforts du CIBP pour faire acquérir cette pièce par le Musée de la ville. Mais le prix de l'adjudication a dépassé sensiblement les prévisions: espérons que l'acquéreur final n'enfouira pas trop jalousement son trésor.

2 Dans le très beau catalogue de la vente ${ }^{1}$, le document est inscrit sous le $n^{\circ} 240$ et fait l'objet d'une photographie qui permet un déchiffrement aisé. Voici la transcription du texte, établie en respectant l'orthographe et la ponctuation originales, sauf menues corrections destinées à éviter les obscurités inutiles². 


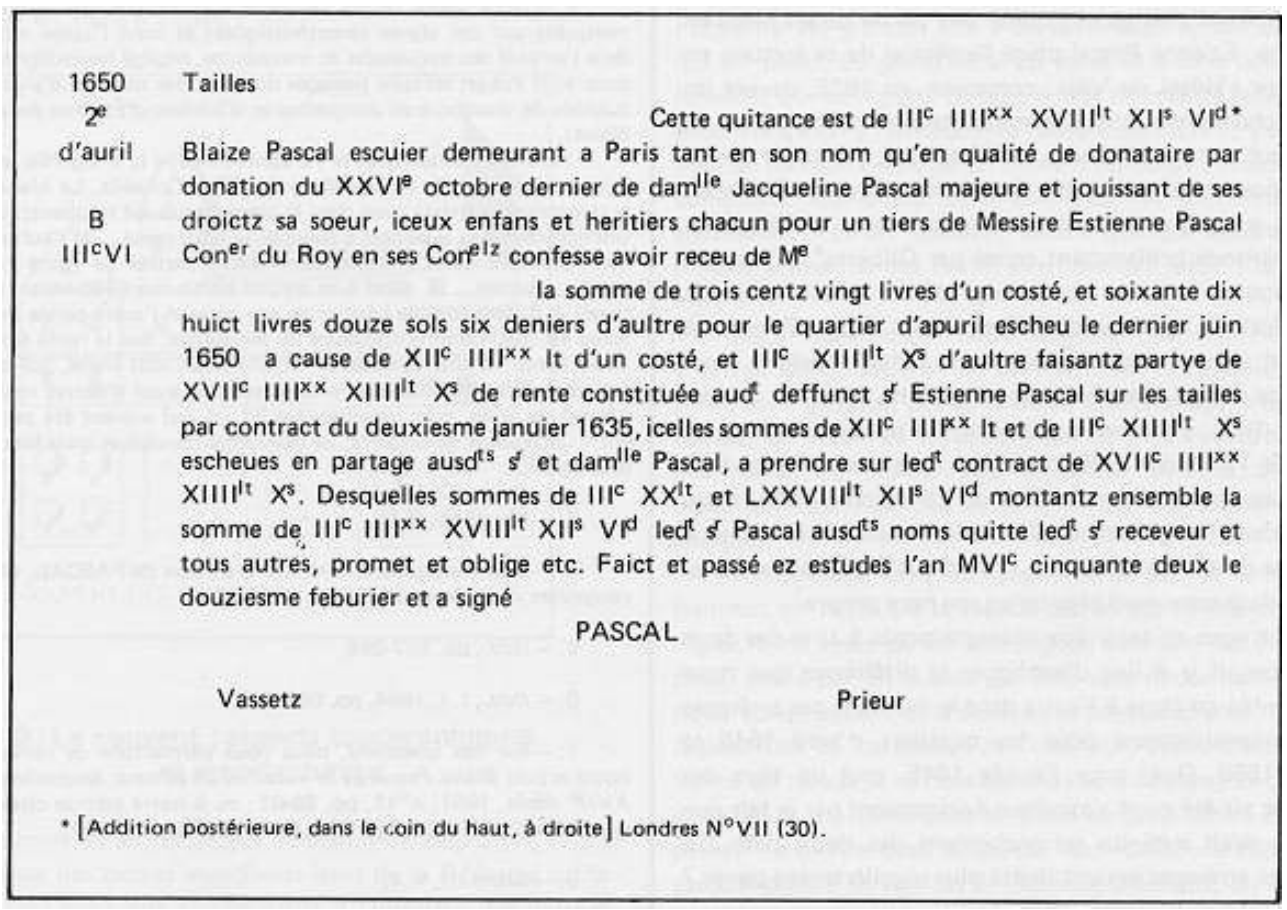

3 Si cette quittance est inédite, elle n'en avait pas moins été déjà remarquée et son texte aurait pu être publié depuis longtemps. Le célèbre érudit Prosper Faugère, premier éditeur du texte intégral des Pensées (1844), en eut connaissance, par une voie que nous ignorons, et en fit établir d'excellents fac-similés : cinq exemplaires s'en trouvent dans la collection de documents pascaliens léguée par lui à la Bibliothèque Mazarine ${ }^{3}$. Seule différence : le fac-similé ne reproduit pas la mention inscrite tardivement dans le coin haut à droite du document et que nous avons nous-même détachée du texte principal dans notre transcription, mention certainement portée à l'occasion d'une vente faite à Londres. Ou bien cette addition est postérieure à la confection du fac-similé, ou bien le graveur qui a établi celui-ci l'aura intentionnellement négligée comme n'appartenant pas à la pièce originale.

Pourquoi le quintuple document $\mathrm{du}$ fonds Faugère n'a-t-il jamais fait l'objet d'une publication? D'abord sans doute parce qu'il n'avait jamais été allégué dans les écrits de celui qui l'avait fait établir. A-t-on cru que la pièce aurait été forgée? Il était impossible de ne pas la reconnaître pour authentique dès lors qu'on la comparait à d'autres actes passés par Pascal à la même époque devant les même notaires ${ }^{4}$. En fait, et l'auteur de ces lignes peut en témoigner à sa honte, le fac-similé a été pris pour la reproduction d'une autre quittance, passée le même jour devant les mêmes notaires, conservée parmi les Pièces originales du Cabinet des Titres à la Bibliothèque Nationale et déjà plusieurs fois publiée $^{5}$. Les deux documents sont fort semblables et il fallait y regarder de près pour les distinguer. Dans un cas comme dans l'autre, Pascal agit à la fois en son nom et comme donataire de sa sœur, et les rentes dont il touche les arrérages sont les mêmes. Les deux actes sont pourtant bien distincts ; entre eux se relèvent les différences suivantes :

$1^{\circ}$ La quittance des Pièces originales porte sur le quartier d'avril (second trimestre) de l'année 1645 ; la quittance inédite sur le même quartier, mais pour l'année 1650.

$2^{\circ}$ Dans la première quittance, seul est payé un tiers du quartier d'avril; dans la seconde, la nôtre, le quartier entier. Aussi bien, en signant la première, Pascal 
touchait-il 132 l. 17 s. 6 d., tiers de la somme de 398 l. 12 s. 6 d. qu'il touche en signant la seconde.

Un commentaire complet de ces deux pièces inséparables obligerait à rappeler comment, en 1635, après avoir abandonné ses charges et liquidé une partie de ses biens en Auvergne, Étienne Pascal plaça l'essentiel de sa fortune en rentes sur l'Hôtel de Ville ; comment, en 1638, devant les « retranchements » dont ces rentes étaient l'objet, il prit part avec d'autres rentiers à une manifestation qui attira contre lui des poursuites, comment il obtient sa grâce de Richelieu par une supplique de la petite Jacqueline au puissant ministre : épisode brillamment conté par Gilberte ${ }^{6}$. Il faudrait aussi évoquer le début du partage de cet ample fonds de rentes lors du mariage de Gilberte avec Florin Périer, en 1641 ; et signaler que ce partage fut achevé, après la mort d'Étienne Pascal, par un acte sous seing privé du 31 décembre 1651, reconnu par-devant les notaires Vassetz et Prieur le 12 février 1652, date des quittances. Il faudrait encore ajouter que par un acte du 26 octobre 1651, mentionné dans les quittances, Jacqueline avait fait donation à son frère de toutes ses rentes, si bien que Blaise pouvait agir au nom de sa sœur aussi bien qu'en son nom propre ${ }^{7}$.

6 Pour nous en tenir aux enseignements à tirer des deux quittances, il y a lieu d'expliquer la différence que nous avons notée de l'une à l'autre dans le montant des arrérages payés respectivement pour les quartiers d'avril 1645 et d'avril 1650. Que, pour l'année 1645, seul un tiers des arrérages ait été payé s'explique évidemment par le fait que la rente avait subi un retranchement des deux tiers. En 1650, les arrérages avaient-ils été plus régulièrement payés ? Il est permis d'en douter. Si le quartier d'avril a été entièrement payé, d'autres sans doute auront été entièrement retranchés. N'oublions pas le vers de Boileau décrivant le pâle visage d'un rentier

À l'aspect d'un arrêt qui retranche un quartiers

7 Les sommes touchées par Blaise le 12 février 1652 correspondaient évidemment à un arriéré laissé par Étienne Pascal dans la perception de ses rentes. On a peine à croire que cet arriéré ait été limité à deux quartiers d'années aussi distantes que 1645 et 1650 . D'autres quittances semblables ont donc sans doute été passées le même jour. L'espoir existe de nouvelles découvertes.

\section{NOTES}

1. Précieux Autographes et Manuscrits Littéraires et divers, Collection d'un Amateur ( $\mathrm{M}^{\mathrm{e}} \mathrm{Jean}$ Morelle, commissaire-priseur ; M. Thierry Bodon, expert).

2. Nous avons résolu certaines abréviations (celles qui sont marquées par des signes caractéristiques) et suivi l'usage moderne dans l'emploi des majuscules et minuscules, négligé les soulignements dont font l'objet certains passages du texte (les sommes d'argent, les qualités de donataire de Jacqueline et d'héritier d'Étienne données à Blaise).

Autres éclaircissements : L'abréviation «It » signifie « livres (tournois) »; Con ${ }^{\text {er }}$ - Conseiller ; Con elz - Conseilz. Le blanc dans la transcription existe aussi dans la pièce (le cas est fréquent). La distinction des deux quartiers à toucher (« d'un costé... de l'aultre... »), correspondant à (« a 
cause de ») deux parties de rente (« d'un costé... d'aultre... »), tient à ce qu'une partie (les 1280 livres) appartenait à Blaisse comme héritier de son père, et l'autre partie (les 314 livres 10 sols) comme donataire de Jacqueline. Sur la rente totale de 1794 livres 10 sols considérée ici, il restait 200 livres, qui étaient échues à Gilberte. Étienne Pascal possédait aussi d'autres rentes sur l'Hôtel de Ville, non mentionnées ici, et qui avaient été partagées entre Jacqueline et Gilberte, de manière à constituer trois lots à peu près égaux.

3. Ms. 4551, II-16.

4. Voir notamment dans notre édition de PASCAL, CEuvres complètes, t. II, Paris, 1970, pp. 887-888.

5. Ibid., pp. 897-898.

6. Ibid., t. I, 1964, pp. 660-662.

7. Sur ces questions, nous nous permettons de renvoyer à notre article Blaise Pascal et la vocation de sa sœur Jacqueline, dans XVII e siècle, 1951, n 11, pp. 69-92; ou à notre édition citée, t. II, pp. 101-102, 111-112, 263-268, 864-879, 889, 897-901.

8. Satire III, v. 4.

\section{INDEX}

Mots-clés : quittance, Pascal 